\title{
La ReCURSividad de la Historia en Mapocho de NonA FERNÁNDEZ*
}

\author{
Ricardo Ferrada**
}

\section{Resumen}

El tema central de este trabajo aborda el dialogismo entre la historia legitimada y la historia ficcionada en la novela Mapocho de Nona Fernández, quien muestra en su texto el cruce de fronteras discursivas, en la cual convergen el pulso vital de la historia y la ficción literaria. A partir de un relato construido desde la recursividad de la historia, se plantea la opción de un contradiscurso, en que las utopías se proyectan desde la sospecha del pasado, además de invitar al lector a (des)articular el hilvanado entre pretérito y presente, llenando las fisuras de la historiografía.

Palabras clave: narrativas, historia legitimada, historia ficcional, contradiscurso.

\section{THE RECURSION OF THE HISTORY IN MAPOCHO NonA FERNÁNDEZ' NOVEL}

\begin{abstract}
The focus of this paper addresses the dialogism between legitimized history and the fictionalyzed history, for which we analyze Mapocho, the Nona Fernandez's novel, who shows in her text discursive crossing borders, where converges the vital pulse of history and the literary fiction. In that sense, from a story constructed from the recursion of the history, the option of a counter- discourse arises in wich the utopias are projected from the suspicion of the past, besides inviting to the reader to (dis) articulate the basting between past and present, filling the cracks of historiography.

Keywords: narratives, legitimized history, fictional history, counter-discourse.
\end{abstract}

Recibido: 12-09-2015

Aceptado: 15-11-2015

* Este artículo se inscribe en un proyecto personal de investigación sobre narrativa chilena del siglo XXI, del cual ya se han publicado algunos trabajos en revistas internacionales.

** Chileno. Doctor en Estudios Americanos, Universidad de Santiago de Chile. Académico de la Universidad Católica Silva Henríquez, Santiago, Chile. jferrada@ucsh.cl 
La ficción trabaja con la creencia y en este sentido conduce a la ideología, a los modelos convencionales de realidad y por supuesto también a las convenciones que hacen verdadero (o ficticio) a un texto. La realidad está tejida de ficciones.

Ricardo Piglia (Crítica y ficción 10-11)

\section{Presentación}

La experiencia de lectura muestra que el contexto de una parte significativa de la novela latinoamericana y chilena en las décadas iniciales del siglo XXI se hace evidente en la trama de conflictos que constituye el mundo narrativo. Pueden mencionarse, por ejemplo, las narrativas que tienen como eje la violencia política, la migración forzada (exilio) o voluntaria (chicanos); el problema del sicariato, el narcotráfico, la marginalidad urbana; la discriminación de género, la infancia traumada, el abandono, etc.

Esta es una materia que conduce a diversas líneas de reflexión crítica, lo que amplía el espacio de los estudios literarios. Desde otra perspectiva, es un campo que hace entrar al debate el aporte creativo de escritores emergentes, cuyas poéticas se desmarcan prudentemente de la tradición literaria, además de tener una etapa formativa que por época no solo incorpora los efectos generados por las globalización, sino que, además, asimilan el telón de fondo de los proyectos culturales y políticos desplazados por la historia, particularmente, el último tercio del siglo $X X$. En este caso, se trata de un componente que permea el estatuto de la ficcionalidad, de modo que esta alcanza una conexión con posibilidades de narrar un espacio de crisis.

En ese contexto, el tema central de este trabajo aborda el dialoguismo entre la historia legitimada y la historia ficcional, para lo cual se analiza en particular la novela chilena Mapocho (2002) de Nona Fernández, en la premisa de que su escritura devela una discusión con la historia legitimada, con lo cual se pone en duda o sospecha la significación cultural y política de las utopías nacionales y sus efectos en el imaginario colectivo. Al respecto, a partir de un relato construido desde la recursividad de la historia, se plantea la opción de un contradiscurso 
que remite a la construcción de una narrativa cultural en que las utopías se proyectan desde la sospecha del pasado; en último término, si bien se trata de una estrategia narrativa, se invita al lector a (des)articular el hilvanado entre pretérito y presente llenando las fisuras legadas por la historiografía.

En términos de escritura, observamos que la construcción narrativa de Mapocho muestra el cruce de fronteras discursivas, transiciones y (re)lecturas del pasado en la cual convergen el pulso vital de la Historia (la hiperbolización del discurso ideológico, un acto de habla masivo apelando a un colectivo) y la ficción literaria, cuyo sentido generador es el interlineado de un modelo de sociedad que predispone la marginalidad social de los sujetos y el olvido de su pasado.

Así pues, la estrategia de análisis que se emplea pone en ejercicio la mirada sobre el sentido de la historia nacional, consecuentemente, actualiza las direcciones que temporalizan el pasado, poniendo en tensión las fracturas que marcan la significación de la memoria colectiva. Por otra parte, desde otro nivel, el trabajo se sitúa en las estrategias contradiscursivas hacia la historia legitimada, evidenciadas en los recursos irónicos, la desmitificación, la dinámica que mueve a los personajes y el uso de la voz externa al mundo narrado, que ponen en entredicho los tópicos con los cuales se elabora la narrativa histórica elaborada por la tradición¹. Desde una perspectiva metodológica, considerando el proceso de ficcionalización, se opera entonces mediante un enfoque que incorpora conceptos provenientes de la narratología y del discurso, en tanto herramientas que propician abrir la lectura crítica hacia nuevas direcciones.

\section{Un recorte sobre novela chilena del siglo XXI}

Para el ámbito particular que abordamos, Mapocho se inscribe en una narrativa cuya recepción hace converger la eventual densidad literaria, su valor expresivo-imaginario, y un modo de entender o discernir los

1 Es relevante aclarar que no obstante lo específico de este artículo, su tema central se inscribe y vincula con un proyecto más amplio en el que intento modelar las líneas de articulación y de ruptura en la narrativa chilena del siglo XXI, particularmente las formas estilísticas y estrategias de escritura que orientan su producción. En ese trabajo amplio, hemos publicado “Los espacios de ficción y realidad en Una casa vacía, de Carlos Cerda", Revista Anales 2, Vol. 12 (2010), Universidad Metropolitana de Venezuela, además de "El montaje y la estrategia de la metanarración en Cercada, de Lina Meruane", Revista Anales 2 Vol. 14, (2014). Por necesidades de contextualización, reiteramos aquí algunos aspectos ya desarrollados previamente. 
fenómenos sociales del pasado, vistas en la perspectiva de una nueva generación de escritores. Si consideramos esos tres elementos en términos de constantes de escritura, puede afirmarse entonces que ellos proyectan la entrada a una nueva época, con asociaciones temáticas y referenciales a un insoslayable eje de la historia nacional, determinante en la vitalidad cultural, esto es, el periodo de la transición política chilena. Siguiendo las palabras del novelista Alejandro Zambra (Formas de volver a casa, 2011), se incorpora en esa fracción de la historia no solo la literatura de los padres, sino que también la literatura de los hijos.

Un aspecto que particulariza el diseño de esa trama de conflictos consiste en que configuran un diálogo con otros discursos que elaboran narrativas o relatos no ficcionales que recomponen e interpretan la experiencia histórica y cultural de ese mismo pasado: la historia política, las tensiones ideológicas, las experiencias testimoniales de la violencia brutal (una forma cultural de lo inhumano), los desarraigos forzados, la contracultura, las acciones de protesta, la articulación de las organizaciones sociales y culturales, el amplio registro documental de imágenes liberado de los depósitos ocultos, luego de años de (auto) censura, incluso los archivos oficiales de la memoria asumidos por el Estado.

En la perspectiva de la producción literaria, los nuevos escritores vienen a proponer la conexión de una realidad empíricamente fragmentada; por otra parte, problematizan en la ficción literaria desde una experiencia vital ajena a ese mundo referido, por cuanto se trata de un grupo de creadores que nacen a mediados de los años 70 del siglo $\mathrm{XX}^{2}$. Generan así un cronotropo situado en que opera una relación dialógica con esas construcciones discursivas no ficcionales, cuya suficiencia interpretativa y estatuto de verdad se pone a prueba para dar cuenta de la memoria histórica y cultural, en la medida que los textos literarios recomponen niveles internos de la realidad y producen un diálogo de épocas, en otras palabras, nos encontramos con obras en las cuales se articula literariamente la ficción narrativa y la historia chilena reciente,

2 En ese aspecto, es claro que se trata de escritores cuyo espacio formativo está marcado por el modelo sociocultural autoritario del gobierno militar. Por otra parte, desde una perspectiva literaria, es un grupo de escritores que se distancia del carácter fundacional que asumió la generación previa, la llamada "nueva narrativa chilena". Sobre este último punto, es altamente referencial el libro de Carlos Olivares (1997) Nueva narrativa chilena. También de Rodrigo Cánovas (2002) el texto "Nuevas voces en la narrativa chilena", en Literatura chilena hoy. 
donde prevalece la dimensión existencial de la experiencia por sobre los discursos de interpretación histórica, sociológica o política.

Ese rasgo, que propicia una cercanía del lector con el mundo narrado, potenciada por los usos del lenguaje, intensifica los niveles de comprensión del pasado histórico a lo menos en tres dimensiones: la dinámica de las relaciones sociales y culturales, marcada por la integración a una nueva modernidad; luego, las situaciones que marcan la memoria colectiva en las utopías de época; por último, en su reverso, los proyectos personales en un espacio en que se ha instalado la crisis. La novela, a partir de su carácter ficticio, puede ser vista entonces como generadora de conocimiento, un atributo que direcciona el nivel argumental de la narración hacia las condiciones textuales que entregan verosimilitud a la realidad construida literariamente -su "efecto de realidad" (Barthes)-, donde asumen relevancia la descripción y los indicios caracterizadores de época.

La pregunta de cómo se configura el mundo narrado lleva entonces no sólo a reflexionar sobre el lenguaje literario, sino que, además, en las obras y sus formas de representar construcciones sobre la experiencia de mundo, o las explicaciones que hacen más comprensible su trama de sentidos. Es el verosímil de Aristóteles, o en paráfrasis con Todorov, un espacio interpretativo que lleva a ponderar las posibilidades culturales de lo imaginario. Así entonces, más allá del escritor/autor y el valor del texto como signo literario, emerge una narrativa que interroga la realidad, en donde el relato se construye en el implícito ideológico, cuyo referente se articula en los metarrelatos del pasado: la utopía generacional de los 70. Entonces, lo implícito del lenguaje no es solamente la experiencia empírica, si consideramos que el mundo real y su transcurso histórico se construyen desde el mundo de la voluntad y el deseo, materializado en un proyecto colectivo.

Ese atributo literario excede la premisa de que lo relatado "refleja" la realidad, la idea de que la literatura constituye una forma metonímica, y que, consecuentemente, conforma casi una cita, que resume en último extremo la totalidad del mundo. De hecho, el poderoso y razonable contraargumento de la suficiencia estética del texto desplaza esa pretensión, cuya certeza encontramos en las propias notas autorales de los escritores. Acorde con Tomás Eloy Martínez, en narrativa todo es imaginario, aunque dé la apariencia de real. "Todos los personajes de esta 
historia, reales o imaginarios, son imaginarios", expresa Nona Fernández en Nota de la autora, al final de Mapocho.

Lo anterior nos hace plantear que la ficción narrativa chilena muestra líneas de articulación y de ruptura que textualizan mundos literarios, a partir de diversas estrategias de escritura, donde el autor se mueve en sus propios dominios para provocar al lector. En ese contexto, entendemos que esas articulaciones se tematizan mediante ejes en torno a los cuales convergen obras cuyo mundo narrado permite observar las marcas autorales de una nueva generación de escritores; desde otra perspectiva, podemos agregar que los tópicos de la ficcionalidad potencian ejes de sentido que se despliegan con entradas y salidas, en que el recurso de la metanarratividad, esto es, una narración que reflexiona sobre sí misma (Eco, 2012) interviene el flujo de lectura, de modo que se desinstala al lector haciéndolo participar de un diseño escritural.

\section{La intriga de una historia en Mapocho}

El pasado tiene la clave. Es un libro abierto con todas las respuestas. Basta mirarlo, revisar sus páginas y abrir los ojos con cuidado para caer en cuenta. El pasado es un lastre del que no hay cómo librarse. Es mejor adoptarlo, darle un nombre, aguacharlo bien aguachado bajo el brazo, porque de lo contrario pena como un ánima con los rostros más inesperados.

Nona Fernández (Mapocho 173)

Se entiende que los discursos que se articulan mediante la construcción narrativa, ya sea en su variante ficticia o no ficticia (van Dijk, 2000; Renkema, 1999), tienen una presencia central en el mantenimiento de la memoria colectiva, valorándose por la calidad de sus resultados de escritura, aun cuando se considera con mayor fuerza su nivel de proximidad con los conflictos o problemáticas de época o de la cultura en que se insertan. Desde otra perspectiva, porque también muestran un mundo de ideas que lo estructura, secuencias de contenidos que se pueden contrastar con fuentes externas y otras discusiones con las cuales dialoga. Es así como destaca la importancia de distintas formas de narrar como son la novela, el cuento, además de la crónica, la memoria, la

3 Todas las citas se hacen sobre la segunda edición, 2008. 
historia, el testimonio, que se definen por su carácter referencial respecto del mundo empírico.

Independientemente de las tipologías, el contenido textual adquiere, siguiendo a Haydn White (1992), un carácter gnoseológico, un metacódigo, que posibilita, eventualmente, ampliar la conciencia y el grado de conocimiento de la realidad, en consecuencia, resignifican el pasado y establecen comprensiones del presente, con lo cual se abre un campo de nuevas relaciones "ideológicas", los valores compartidos por una comunidad, según propone Teun van Dijk en Ideología (21). Precisamente por ello -agregamos-, Mapocho es una novela que demanda un ejercicio metodológico que integre el nivel del discurso narrativo y la ficcionalización a la experiencia del lector, con su juicio sobre la Historia histórica.

Cualquiera sea su modalidad o estrategia de escritura, la narrativa hace implicar modos de leer y el desafío de validar adecuadamente el contenido textual. En analogía con lo señalado por Félix Martínez Bonatti (2001), el receptor acude a dimensiones extratextuales que le aportan elementos de juicio con los cuales (re)elabora el mundo de palabras que se le propone, su verosimilitud o el ajuste a la posible verdad cuando se trata de registros que poseen carácter histórico.

En ese esquema, Mapocho de Nona Fernández nos propone una escritura que dialoga con el eje de narrativas culturales ${ }^{4}$, donde encontramos un relato construido en líneas discontinuas de acción, que al activar distintas temporalidades, despliegan la duda o sospecha sobre la significación cultural y política de las utopías nacionales y sus efectos en el imaginario colectivo: la revelación de un modelo de sociedad que termina en la marginalidad social de los sujetos y el olvido de su pasado.

Para lograr ese efecto, la voz narrativa anticipa el relato de hechos después de que han sucedido, rememorados en un presente (pasado histórico); también entrega la narración imaginaria de sucesos a medida que suceden (presente continuo), y la narración anterior-profética, en cuanto existe el adelanto de algo que sucederá en el futuro (catáfora).

4 Es una denominación con la cual aludimos a un tipo de narrativa en que el mundo narrado se construye desde fronteras discursivas, con (re)lecturas del pasado, en que convergen el pulso vital de la historia y la ficción literaria, cuyo sentido proyecta un interlineado que valida el espesor de la memoria y la significación cultural de las utopías. 
La historia central de la novela desarrolla un conflicto familiar en el contexto de la dictadura militar: la Rucia, el Indio (dos hermanos adolescentes), la madre, el exilio. El padre es aparentemente un desaparecido, luego de haber sido hecho prisionero por los militares. En esta situación va a confluir la principal línea de la intriga, ya que el transcurso de toda el relato, estará enfocado en la búsqueda para entender qué ocurrió con el padre, una situación que en realidad es manipulada por la madre quien se resiste a contar la penosa verdad a sus hijos: el vínculo de Fausto -el padre- con los militares, quien se transformó, a poco de andar, en el historiador oficial de la dictadura.

Él escribe y la Historia del país aparece irrevocable en las páginas de sus libros. Los niños la aprenden en el colegio, los adultos la leen en las bibliotecas, los ancianos la reciben de regalo en lugar del cheque de aguinaldo para fin de año. Poco a poco su historia se va legitimando, va ganando terreno, va anulando a las otras cosas, a esas que han sido sacadas de los anaqueles, de las listas escolares, de las librerías, hasta de las tiendas de libros usados. Su versión es la correcta. Lo que él ha escrito existe y lo que no, bien merece ser olvidado. Ése fue el trabajo que le dieron por hacer. (Fernández 39)

El eje de la intriga se construye entonces a partir de los diversos avatares de esa búsqueda, el encuentro del origen, mostrado por una voz narrativa que cambia de foco acorde a los distintos momentos históricos que se narran. Así, con un tiempo narrativo en reversa (pasado y presente), asistimos al proceso simbólico de la muerte ya anunciada de la protagonista, donde el rito termina en el curso del río Mapocho, cuyo cauce recorre y divide la ciudad en secciones y que conduce finalmente hacia el escenario del antiguo barrio. Paralelamente, también aparece otro punto axial que percibe la abuela, con el cual no solo orienta a su nieta, sino que, además, le ayuda a categorizar y a entender el mundo urbano que habitan:

Cada vez que te pierdas, Rucia, recuerda que vivimos mirando el poto de la Virgen. La doña no tiene ojos para nosotros, sólo mira a los que están al otro lado del río, así es que mientras el resto de la ciudad le reza a su cara piadosa, nosotros nos conformamos con su traste, que por lo demás no está nada de mal, todo blanco y de loza, todo casto y puro, el poto de la Virgen. (27) 
Empíricamente-advertimos-, el río Mapocho constituye por naturaleza un demarcador de la geografía urbana, que en el espacio prehispánico y colonial, aparece límpido, aunque violento y amenazador en el invierno; no obstante, en la sociedad futura no solo dividirá la ciudad capital estableciendo un orden de clase que se naturaliza, sino que además arrastrará los desechos y luego la historia sucia de la violencia, con la imagen sagrada en esa cumbre que menciona la abuela.

Acorde a lo señalado por Cristián Opazo en el título de su trabajo (2004), la novela Mapocho muestra "la inversión del romance nacional", por cuanto mediante una forma alegórica, se narra el fracaso del proyecto de ascenso social proveniente de fines del siglo XIX. La separación de la familia de Fausto y el fin trágico del encuentro, en verdad, dispondría un mundo en que decae todo el orden imaginado, cuya materialidad es una sociedad que se transforma por la imposición de un nuevo modelo, de modo que los valores que determinan las relaciones, desplazan la posibilidad de construir el sujeto que asciende e influye en las direcciones del colectivo nacional.

Si recordamos el planteamiento de Homi Bhabha acerca de que "Los orígenes de las naciones, como de las narraciones, se pierden en los mitos del tiempo" (11), Mapocho dialoga con una forma deconstructiva de la nación, o la idea histórica de la nación. En ese contexto, esa alegoría que observa Opazo llevaría a pensar que el relato es un símbolo abstracto, que demanda desmontar sus conexiones de sentido, por cuanto es una narración encriptada plena de símbolos que abstraen el transcurso de la Historia: la evocación de personajes históricos cuya vida privada marca el carácter de lo nacional; la virgen del cerro descrita por la abuela; el barrio pobre y decadente que se lleva la infancia; el personaje fatídico del historiador que sanciona y omite aspectos incómodos del pasado; la voz fantasmal de la fallecida Rucia que nos relata su propia muerte:

Nací maldita. Desde la concha de mi madre hasta el cajón en el que ahora descanso. Un aura de mierda me acompaña, un mojón instalado en el centro de mi cabeza, como el medio melón de los piantaos, pero más hediondo, menos lírico. Nací cagada. Desde el juanete del pie hasta la última mecha desteñida que me cuelga de la nuca. Me escupieron y fui a dar al fin del mundo, al sur de todo. Un gargajo estampado en ese rincón que se cae del mapa. Ahora mi cuerpo flota sobre 
el oleaje del Mapocho, mi cajón navega entre aguas sucias, haciéndole el quite a los neumáticos, a las ramas, avanza lentamente cruzando la ciudad completa. (13)

En el repliegue de esa historia, se puede entender que la dinámica social se potencia en el despliegue de un binarismo ideológico que escapa a la dialéctica clásica, dada por la singular resolución de los conflictos sociales: el fracaso de un proceso, la utopía, una orgánica ideológica cuya actualización se desplaza hacia el fin de su propio relato, transformado en una "escritura del desastre" y la marginalidad, que alude a los vestigios y remanentes de un duelo nacional, la cita historiada de la muerte, o la muerte de la propia protagonista que cita la historia narrada.

Entonces, la multiplicidad de actos o momentos narrativos que se insertan en la duración del relato, más que adscribirse a una estrategia distinta de temporalizar, sugiere una visión sobre las constantes que han orientado el acontecer nacional, en que se alternan y convergen sujetos que marcan trayectorias, huellas que requieren ser descifradas, con trazos que derivan en la posibilidad de un eventual sentido en el recuerdo de la patria con la imagen alegórica de la casa:

Dicen que Chile era una casa vieja, larga y flaca como una culebra, con un pasillo lleno de puertas abiertas por donde la gente se paseaba entre todas las piezas. Dicen que olía a empanada y chicha, que tenía una cordillera en el patio de atrás y un sauce llorón que lloraba poco, porque hasta entonces no tenía muchos motivos para hacerlo. Dicen que la casa estaba pintada de verde, que cardenales rojos le salían por las ventanas, que un par de escalones colorados inauguraban la fachada y que tenía una mampara con cristales rugosos por donde todos entraban y salían sin problemas, libres de hacerlo cuando quisieran. Dicen que las cosas funcionaban bien en la casa. Había muchas piezas, con espacio para bastante gente, así es que no querías ver a alguno, bastaba con no entrar a su cuarto y hacerle el quite en el pasillo o en el patio, si es que no lo divisabas de lejos. En el sector norte vivían los mineros. En el centro, los profesores. Los ferrocarrileros contaban con piezas pequeñas a lo largo de todo el pasillo. Los obreros estaban achoclonados en un cuartucho chico cerca de la cocina, y así cada cual tenía su rincón en la casa. (135) 
La imagen de la casa, entonces, termina por sintetizar todos los tiempos y la orgánica de un proyecto de país; una construcción maqueteada de la geografía social y humana en que convergen y se articula la trama de sentidos (Geertz) que constituye la cultura nacional, diferenciada en estratos y espacios de relación que evocan una gran casa de inquilinato, la vecindad del conventillo chileno en la barriada popular al lado norte del río Mapocho.

\section{La recursividad de la historia}

En la perspectiva de una problematización de la novela, estimamos que una propuesta central de Fernández se orienta a entender, antes que la Historia de Chile o los tiempos de la historia, la recursividad de la Historia nacional. En otras palabras, pone en diálogo la construcción de su sentido, que remite a la voluntad del pasado y los sujetos que la construyen en su presente, antes de que llegara el documento legitimador del discurso organizado del acontecer, que omite o invisibiliza la ética de las subjetividades, el lugar que abre precisamente las opciones de lectura de ese pasado. En esos términos, la narración se desplaza en el (des) orden convergente de hechos que han marcado el imaginario cultural de la patria, el campo de la trascendencia cotidiana en que opera el continuo revelador de la memoria colectiva, el comentario, el rumor.

La disposición del transcurso en la novela, si bien legitima una estrategia de escritura, evoca un rasgo que propone una perspectiva desmitificadora de la construcción nacional; dicho de otro modo, esa recursividad plantea una lectura de los ejes que mueven la historia nacional, afín a la tendencia de la llamada "nueva novela histórica" (Menton, 1993), en que la ficción despliega construcciones alternativas del pasado, o a lo menos conduce a que se rompan las fórmulas consolidadas de su herencia en el presente. La desestabilización de los íconos pone entonces al lector ante una nueva territorialidad, cuyos límites fusionan, antes que la geografía, el pasado y el presente en la ceremonia del duelo y el fantasma reiterado del deseo. Es una nueva visión de la historia, construida sobre hechos inicuos y detestables.

Así pues, la disposición de la trama (la textura) configura la tensión de toda la novela, en que de modo paradojal los intersticios entre las secuencias de acción operan con sentidos sobrearticulados, considerando los permanentes ensambles de la historia del pasado-futuro con el 
presente, una forma de "imaginación dialógica" (Bajtin, 2002). De ahí que el lector deba colaborar en el armado del flujo narrativo, cubrir los vacíos entre las secuencias de acción, tensionar las indeterminaciones, aventurar en la sospecha del momento posterior, juzgar a los personajes (la relación entre la Rucia y el Indio, el encuentro con el padre), luego de conocida su verdad, considerando cada uno de los discursos parciales que narran, alternadamente, la historia nacional, hasta llegar a la crisis de la república, materializada en la historia familiar de la Rucia, quien procura el retorno a su lugar de origen y solo encuentra la muerte.

Entonces, mediante la alternancia de tiempos, asistimos a distintos momentos fundacionales del pasado chileno y sus nombres emblemáticos, observados desde una distancia o perspectiva contrahistórica: la conquista con Pedro de Valdivia y Lautaro; la colonia mediante la figura de Luis Manuel de Zañartu; la independencia y Bernardo O’Higgins, la república en el periodo de Carlos Ibáñez del Campo; la caída de la república con la dictadura de Augusto Pinochet, que da término violento al gobierno de Salvador Allende.

Según ese contexto, en la novela (con)fluyen diversos momentos de la historia chilena, en episodios alternados con una voz externa del narrador central, los cuales convergen en puntos de intersección con el relato de la Rucia y el Indio, lo cual genera el sentido de la trama finalmente. Se diluye así la convención de la historia básica, mediante la voz sobrepuesta de los hermanos, quienes se apelan y discuten las circunstancias de un pasado y un presente, con un narrador básico que hace entrar todos los episodios $\mathrm{y}$ referentes de la historia nacional, operado en el montaje narrativo y fundiéndolos en el tiempo de la escritura.

El asunto es que en la novela la acción de los personajes, antes que signada por los hechos memorables que modelan o guían el transcurso de la vida pública, está supeditada a la voluntad desbocada y el secreto del deseo, iniciada en el relato con la relación sodomítica de Pedro de Valdivia y Lautaro, el joven mapuche, líder de la revuelta contra los españoles en la conquista:

Dicen que era verano y que el mapuche estaba medio pilucho, abrigado con el calor de los caballos y con su piel gruesa que soportaba las heladas sin tanto quejido. Dicen que el español llegó con un cuchillo en la mano y que se le acercó silencioso 
hasta rozarle los cabellos con la yema de los dedos [...] dicen que le lamió la nuca y que inspiraba profundo tratando de tragarse todo el olor, todas las ideas, todos los misterios de esa cabeza. Dicen que quería comérselo. Su boca succionando el cráneo del mapuche. Sus labios balbuceando su nombre. Lautaro, decían. Sus manos comenzaron a bajar por el cuello y a apoderarse del cuerpo indígena. Sus dedos reptando por los hombros, por la espalda, tratando de capturarlo por completo, de consumirlo entero. Dicen que le tomó las piernas y que se le metió en el cuerpo como hace mucho quería hacer. Sus barbas mojadas de baba, goteando sobre la melena lacia. Sus bigotes castaños, pegoteado de sudor, mezclándose con los pelos negros de indio. Lo chupaba, lo lengüeteaba entero y el mapuche aceptaba en silencio cada nueva embestida de la lengua española. (44-5)

Ese mismo deseo disparatado luego se proyectará, narrativamente, en las historias que marcan la historia nacional, transformando la imagen icónica de los personajes, mediante la inserción de formas prohibidas del orden social y moral. Así, el corregidor Zañartu, quien ordena construir un puente en la colonia, manifiesta su inclinación pedofílica con sus hijas; O'Higgins, padre de la patria e hijo ilegítimo ("guacho") tampoco reconoce la paternidad de su hijo en Perú; el general Ibáñez, el presidente que persiguió a los homosexuales, es sorprendido en una fiesta trasvestido en mujer. El paroxismo extremo se da en los nobles militares de Pinochet, quienes dan muerte a una joven en una violación múltiple. En esa misma línea de continuidad histórica, aparece la ambigua relación incestuosa de la protagonista (la Rucia) y su hermano (el Indio).

Puede observarse entonces que si la incorporación de la Historia acciona la presencia de episodios, sujetos históricos reales, conflictos clave de la historia nacional, configurantes de la memoria chilena, estos serán abordados mostrándonos aspectos improcedentes para esa historia legitimada. De este modo se les desacraliza, desmitifica, parodiza y antiheroiza, se les baja de su carácter monumental o áurico en la historia oficial.

En tal sentido, afirmamos que en la novela se muestra un contradiscurso de las citas históricas, que opera, interviene, tacha u omite una narrativa desde la misma narración, con lo cual se pone en evidencia 
la construcción discursiva de la historia (White): la voz narrativa que se neutraliza, el mismo Fausto que imaginó ser un escritor y entiende que la historia también se narra, el efecto de una metanarratividad que desfamiliariza la convención lectora:

Fausto piensa que la Historia es literatura. De otra manera él jamás se habría acercado a ella. La Historia, cree él, se inventa a partir de las palabras, como un verdadero acto de ilusionismo. Luz, pronuncia Fausto, junta su lengua y su paladar y emite el sonido mágico a la vez que enciende la lámpara de pie que está a su lado. La luz se hace en el escritorio. (37)

Días después, el 12 de febrero de 1541, don Pedro funda su ciudad con el nombre de Santiago de la Nueva Extremadura. Santiago como el apóstol que cuidaba a los conquistadores, y de la Nueva Extremadura, porque qué otra cosa sería esta ciudad sino un reflejo de aquella otra donde había nacido. Una copia, un armado hecho con los trozos sueltos que la memoria del conquistador guardaba. Un remedo extraño donde indios visten ropas de seda y rezan a vírgenes blancas. Una fotocopia desteñida [...].

Pero no. Esos comentarios fueron suprimidos. Fausto comenzó a entender la lógica del trabajo y él mismo cercenaba sus textos para cumplir bien. (41)

Un plano del relato que hace un giro en el ensamble, la posición de la mirada y del discurso (la secuencia de acciones) opera en la expresión "dicen", "eso dicen" y que produce cambio de temporalidad y el compromiso indeterminado de la voz narrativa en la novela. Se pasa de la primera persona (la voz de la protagonista), al modo impersonal, que incorpora una voz colectiva y anónima, legendaria, cercana al rumor y al chisme. Paradojalmente, la expresión da la entrada a distintos episodios históricos nacionales ficcionalizados en la novela, la construcción de un nuevo relato que pone en duda o ironiza la historia legitimada, un discurso que dialoga intertextualmente con la cita intervenida en la historia escrita por Fausto:

Dicen que Lautaro tenía quince años cuando Don Pedro de Valdivia lo tomó prisionero allá en el sur. Dicen que al conquistador le cayó bien el mapuchito porque tenía los ojos 
brillantes como una aceituna y la piel morena y fresca. Dicen que por eso se lo llevó al campamento y lo convirtió en su paje personal. Lo puso al cuidado de sus caballos. Le enseñó a montarlos y le reveló todos sus secretos. Pronto Lautaro se convirtió en un gran jinete. Galopaba días enteros de un lado a otro frente a la mirada de su patrón. Indio vestido con plumas y sedas, con el pelo desordenado por el movimiento del caballo. Indio de labios gruesos gritando palabras indescifrables, los muslos firmes aferrados al animal el sudor del pecho corriéndole a gotas, mojando la camisa blanca. A Valdivia le gustaba el mapuche. (43)

Entonces, en la perspectiva del efecto sobre el discurso de la memoria histórica, el fondo del relato se orienta a discutir y desestabilizar formas establecidas de la cultura, proponiendo nuevas conexiones de la historia nacional, materializada en la experiencia real-imaginaria de los sujetos y otras formas del discurso que puede vehicular esa posibilidad: ficción, melodrama, testimonio, memoria, leyenda. La novela Mapocho, en su heterodiscursividad, provoca la entrada a estrategias de escritura y, consecuentemente, el desafío de leer desde otro horizonte para construir nuevos sentidos. Esto nos lleva a afirmar que el mundo narrado que construye Nona Fernández, desde la recursividad del impulso que mueve la historia -el deseo-, discute el discurso de la nacionalidad, relevándose un modelo de sociedad que concluye en la presentización. Esto se expresa en los modos en que se niega el pasado, lo difuso convertido en olvido o el tachado voluntario de la memoria.

Literariamente, todo deviene en voces fantasmales como la Rucia, quien narra y anticipa, desde el primer párrafo, su propia muerte -un guiño literario a Juan Rulfo-, mientras su cuerpo flota "sobre el oleaje del Mapocho, mi cajón navega entre aguas sucias haciéndole el quite a los neumáticos, a las ramas" (Fernández 13).

Es el mismo locus cuyo acontecer cotidiano, en el pasado, vería ella misma interrumpido por la violencia, y que abre la lectura política de toda la novela: "De pronto en la ribera del río, un grupo de cuerpos aparecieron derrumbados unos sobre otros. Todos hombres. Todos con las manos atadas en la espalda. Estaban casi desnudos. Llevaban los pantalones abajo, a la altura de los tobillos, y el torso descubierto y ensangrentado. Las aguas del río los mojaban y limpiaban de a poco" (133). 
Mapocho muestra entonces los niveles paralelos de una sucesión imaginaria, la narrativa de un posible imaginario: la equivalencia de la microhistoria familiar y la macrohistoria nacional; en otras palabras, el relato desgarrador de la separación y el develamiento de la verdad, la agnórisis del encuentro que deviene en tragedia, envuelta en la trayectoria de un proyecto fracasado de país y el duelo inconcluso de sus muertos llevados por las aguas del río.

\section{Conclusiones}

El desastre está del lado del olvido; el olvido sin memoria, el retraimiento inmóvil de lo que no ha sido trazado -lo inmemorial quizás [...].

Maurice Blanchot (La escritura del desastre 11)

Si hacemos la tradicional pregunta sobre la función del discurso narrativo, en el caso de Mapocho opera el implícito del alcance (o calce) de la "narratividad" con la historia, el transcurso que se "entrama" con el hallazgo de alguna verdad que pueda en encontrarse en el texto. En ese sentido, el escritor estaría en condiciones de proporcionar a los lectores componentes que exceden su enunciado, en la premisa de que hay proximidad con el conocimiento -que define después de todo el carácter temporalizador de toda narrativa-; en otras palabras, la historicidad de los contextos que se narran, el valor de la descripción, donde los lectores entienden y asumen ese proceso como un modo dialógico de aproximarse al mundo empírico.

El problema de la relación entre literatura e historia se sostiene entonces, en las formas de expresión que la configuran, el discurso de lo imaginario y el discurso de lo real. No obstante, la narración pone en entredicho esa consistente diferencia, haciendo fluctuar o suspendiendo el relato de la historia, una construcción cuyo estatuto de verdad se pone a prueba y solo deviene en un "verosímil", donde la ficción novelesca abre la puerta de un otro posible, el lado interno de la realidad, la posibilidad cultural de lo imaginario, en que el lector tendrá la última palabra.

La complejidad del relato construido por Fernández deviene en un ejercicio de lectura que nos somete a la exigencia de la transtextualidad, donde se observan géneros internos y formaciones discursivas, organizadas desde una forma de la literatura fantástica, la fantasmagoría 
de la voz y los muertos (Rulfo mediante, ya señalamos), cruzada por el narrador básico que se despliega por narrativas fundacionales de la historia de Chile.

Esa condición hemos visto que, técnicamente, se disuelve en la confluencia de distintas voces narrativas; en ese sentido, la pluralidad (polifonía) diluye las opciones de lecturas lineales que permitan resolver la intriga. En la práctica, cada narrador asume distintas funciones en la composición de la novela y agrega un ángulo propio a la historia de los personajes centrales que dan la entrada a la memoria histórica nacional (la Historia histórica). De hecho, sus voces se articulan en la necesidad de resolver el secreto familiar (la historia ficticia) con la cual se construye el discurso contrahistórico: el inicio y desenlace de Mapocho enmarca la intrahistoria nacional, esto es, la voz del alma en pena de la Rucia (la muerte) y el Indio (su hermano), que evoca el tránsito de su tragedia en el presente ficticio (el duelo).

En la novela Mapocho, el fundido -pasado y presente- marca una línea de sentido que excede la experimentación con un posible mundo literario, en la medida que la zona articuladora es la no existencia de la muerte. Así, la historia relatada se condensa y despliega en la ambigüedad, donde la voz fantasmal de la protagonista coexiste y aclara las dudas de su origen una vez fallecida, sobrepasada por el trauma de la violencia que arrasó con el barrio y el país, y solo es un alma en pena que navega en el río Mapocho, y que aún así, es interpelada por la voz de su hermano. Entonces, de alguna manera, la familia separada deviene en una alegoría de la nación, donde el lector se hace cómplice de un transcurso del cual se le han entregado las claves operando en la metanarratividad del texto: la historia se cuestiona y no termina en sí misma, sino en la construcción imaginaria que se despliega en el ritmo del tiempo, discute la historia legitimada y la ideología el poder que se instala cíclicamente en la historia, oculta en el deseo. 


\section{Bibliografía}

a. Corpus

Fernández, Nona. [2002]. Mapocho. Santiago: Uqbar editores. 2008

\section{b. Estudios teóricos}

Bhaba, Homi. [1990]. “Introducción”. Nación y narración. México: Siglo XXI Editores, 2010.

Bajtin, Mijail. Estética de la creación verbal. México: Siglo XXI Editores, 2002.

Barthes, Roland. "El efecto de realidad". El susurro del lenguaje. Buenos Aires: Paidós, 2002.

Benjamin, Walter. El narrador. Santiago de Chile: Metales Pesados, 2010.

Burke, Peter. Hibridismo cultural. Sao Paulo: Unisinos, 2010. - ¿Qué es la historia cultural? Barcelona: Paidós, 2004.

Eco, Umberto. El superhombre de masas. Barcelona: DeBolsillo, 2012.

Geertz Clifford. La interpretación de las culturas. Barcelona: Gedisa, 1998.

Iser, Wolfang. "La realidad de la ficción”. Estética de la recepción. Madrid: Visor, 1989.

Godzich, Wlad. Teoría literaria y crítica de la cultura. Valencia: Frónesis, 1998.

Gotschlich, Guillermo. "Entrevista a Cedomil Goic". Revista chilena de literatura 75 (2009): 317-323.

Jitrik, Noé. "I. Hacia un escenario para el concepto de discurso". El balcón barroco. México: Unam, 1988.

Martínez Bonatti, Félix. La ficción narrativa. Santiago: Lom, 2001.

Piglia, Ricardo. Crítica y ficción. Barcelona: Anagrama, 2001.

Renkema, Jan. Introducción a los estudios de discurso. Barcelona: Gedisa, 1999.

Todorov, Zvetan. Simbolismo e interpretación. Caracas: Monte Ávila Editores, 1992. 
Van Dijk, Teun. Ideología. Barcelona: Gedisa, 2000

White, Hayden. El contenido de la forma. Narrativa, discurso y representación de la historia. Buenos Aires: Paidós, 1992.

\section{c. Estudios literarios}

Areco Morales, Macarena. “Mapocho de Nona Fernández: novela híbrida entre la historia y el folletín". Anales de Literatura Chilena 15 (2011): 219-232.

Avelar, Idelber. Alegorías de la derrota. La ficción postdictatorial y el trabajo del duelo. Santiago: Cuarto Propio, 2011.

Cánovas, Rodrigo. Novela chilena. Nuevas generaciones. El abordaje de los huérfanos. Santiago: Ediciones. Universidad Católica, 1997.

. "Nuevas voces en la narrativa chilena". Literatura chilena hoy. Simposio sobre literatura chilena actual. Karl Kohut y José Morales Saravia (Eds.). Alemania, España: Universidad Católica de Eichstatt, Vervuert VerlagIberoamericana, 2002.

Carreño, Rubí. Memorias del nuevo siglo. Jóvenes, trabajadores y artistas en la novela chilena reciente. Santiago: Cuarto Propio, 2009.

Del Río, Ana María. "Literatura chilena: generación de los ochenta. Detonantes y rasgos generacionales". Literatura chilena hoy. Simposio sobre literatura chilena actual. Karl Kohut y José Morales Saravia (Eds.). Alemania, Madrid: Universidad Católica de Eichstatt, Vervuert Verlag-Iberoamericana, 2002.

Ferrada, Ricardo. "Los espacios de ficción y realidad en Una casa vacía de Carlos Cerda". Revista Anales de la Universidad Metropolitana de Venezuela 2 Vol.10 (2010): 205-224.

Franz, Carlos. "Para una ficción chilena artística (a partir de Donoso)". Literatura chilena hoy. Simposio sobre literatura chilena actual. Karl Kohut y José Morales Saravia 
(Eds.). Alemania, Madrid: Universidad Católica de Eichstatt, Vervuert Verlag-Iberoamericana, 2002.

Guaquiante Blaskovic Lenka. "Mapocho de Nona Fernández: herida y palabra callada". LetrasS5. Web. 2010.<http:/ / www. letras.s5.com/nf131010.html>Visita: 7/11/2015

Jeftanovic, Andrea. "Mapocho de Nona Fernández: la ciudad entre la colonización y la globalización". Chasqui 36 (2007): 73-84.

Llanos, Bernardita. "La espacialización de la memoria en Nona Fernández y Carmen Castillo". Magda Sepúlveda Eriz (Ed.). Chile urbano: la ciudad en la literatura y el cine. Santiago: Cuarto Propio, 2013.

Lillo, Mario. "La novela de la dictadora en Chile". Revista Alpha 29 (2009): 41-54.

Marks, Camilo. Canon. Cenizas y diamantes de la narrativa chilena. Santiago: Debate, 2010.

Menton, Seymour. La nueva novela histórica de la América Latina (19971992). México: FCE, 1993.

Olivares, Carlos. Nueva narrativa chilena. Santiago: Lom, 1997.

Opazo, Cristián. "Mapocho, de Nona Fernández: la inversión del romance nacional". Revista Chilena de Literatura 64 (2004): 2945.

Promis, José. La novela chilena del último siglo. Santiago: Editorial La Noria, 1993.

Salazar, Jezreel. "El silencio narrativo". Revista Palabrijes 2 (2008): 6-10.

Vásquez, Malva Marina. “Memoria urbana y ciudadanías abyectas: Nona Fernández". Magda Sepúlveda Eriz (Ed.). Chile urbano: la ciudad en la literatura y el cine. Santiago: Cuarto Propio, 2013. 